\section{Penicillin-induced epileptogenic foci in the} rat cortex ${ }^{1}$

MARJORIE SCHUMAN, ${ }^{2}$ University of Michigan, Ann Arbor, Mich. 48104, and ROBERT L. ISAACSON, University of Florida, Gainesville, Fla. 32601

This study describes some behavioral consequences of a penicillin-induced cortical epileptogenic focus in the rat. Animals given a unilateral intracortical injection of penicillin in the posterolateral neocortex are more active than are control animals receiving an injection of saline into the same region. No differences were found in the learning and reversal of a spatial discrimination to final criterion performance, but there was a suggestion that the rate of learning might be different in the two groups.

Various pharmacological substances applied topically to neural tissue produce epileptiform electrographic disturbances and have been used to create experimental models of the epileptic process. Among the epileptogenic compounds that have been used are certain antibiotics, including penicillin.

The behavioral correlates of epileptogenic foci are of obvious clinical and experimental interest. The presence of an irritative focus has been shown to disrupt neural function in a way that extirpation of tissue does not. Kraft, Obrist, \& Pribram (1960) showed that bilateral alumina gel foci in the striate cortex of the monkey impaired the acquisition of a visual-discrimination problem, although actual tissue damage was minimal. On the other hand, the retention of a learned preoperative discrimination was not affected. Chow \& Obrist (1954) found that prestriate epileptic lesions did not impair the retention of a visual discrimination. These results suggest that the visual neocortical areas must retain a degree of normal function for visual learning to occur, but that once learning has been accomplished, the functional integrity of cortical tissue is less important for performance. Stamm \& Pribram (1960) have reported similar results for a delayed-alternation problem with epileptogenic lesions in the prefrontal cortex of monkeys.

Very little work has been done on the behavioral correlates of experimental epilepsy in the rat. As an initial approach, we investigated some possible behavioral consequences of epileptogenic lesions in the rat, using an activity measure, a measure of spontaneous alternation, and the learning of spatial discrimination with two reversals of the habit.

\section{METHOD}

The Ss were 30 naive male albino rats, approximately 3 months old at the time of surgery. Ten Ss had penicillin injected into the posterolateral neocortex of one hemisphere. Ten additional Ss received an intracortical injection of saline as a control procedure. The 10 remaining Ss were given intracortical injections of saline bilaterally.

Activity was measured in an open-field maze. The maze was constructed of wood, with an interior area of $30 \times 30$ in. and a height of $7 \mathrm{in}$. The interior was painted gray. The floor was painted with black lines that divided it into 36 squares, each $5 \times 5$ in. In the spontaneous-alternation and spatial-learning procedures, a wooden T-maze was used. The distance from the startbox to the choice point was 12 in., while the distance from the choice point to the goalbox measured 19 in. The goalboxes were $4 \frac{1}{4} \times 11^{3 / 4}$ in. The startbox was $31 / 2 \times 6$ in.

\section{PROCEDURE}

The Ss were anesthetized with sodium pentobarbital $(50 \mathrm{mg} / \mathrm{kg}$ i.p.), with supplementary administration of atropine as needed. After retraction of the scalp, holes were trephined over the posterior cortex of one or both hemispheres. A droplet of S-R penicillin (Parke-Davis) in an aqueous solution of $400,000 \mathrm{U} / \mathrm{ml}$ or an equal droplet of saline was injected subdurally. The penicillin preparation is a buffered mixture of procaine penicillin and sodium penicillin $\mathrm{G}$. These ingredients are present in the mixture in the ratio $3: 1$. The scalp was subsequently closed by sutures. A postoperative recovery period of 12 days (average) was allowed before behavioral testing.

After the recovery period, a food-deprivation program was initiated to maintain Ss at $80 \%$ of their ad lib weights. Water was continuously available in the home cage.

When the Ss had reached their appropriate weights, their activity was measured in the open field in a 7 -min session on 2 consecutive days. The path of each $S$ was traced and scored for the number of lines crossed per session. Spontaneous alternation was measured on the day following open-field testing. For 4 days, Ss were placed in the starting position of the T-maze, and their responses at the choice point were recorded. No rewards for choices were given. Two trials were given on the 1st and 2nd days, while five trials were given each day on Days 3 and 4 . The general procedures described by Douglas \& Isaacson (1965) were followed.

In the position training, Ss were trained to approach their least preferred side as de termined during the spontaneous-alternation test. A $97-\mathrm{mg}$ food pellet was provided as a reward. A preliminary trial was given first in which S was confined for $2 \mathrm{~min}$ in the "correct" goalbox with reward available. Thereafter, 10 free-choice trials were given each day. Ss were trained to a criterion of $80 \%$ or more correct responses on 2 consecutive days. Following acquisition, performance-reversal training was begun. The procedure was the same as for acquisition, except that Ss were rewarded for choosing the side opposite to that which had been rewarded during acqusition training. When criterion had been reached, Ss were reversed again with the correct side being the same as in acquisition. After training, the animals were anesthetized with sodium pentobarbital, and electrical recordings were made from frontal and posterior neocortical areas. Both bipolar and monopolar records were made from the posterior leads, but only monopolar records were obtained from the frontal leads.

\section{Histology}

Immediately following the completion of the electrical recordings, Ss were perfused with $0.9 \%$ saline followed by $10 \%$ formalin, and the brains were removed for histological analysis. They were infiltrated and embedded with paraffin, sectioned at $20 \mu$, mounted and stained with thionin.

RESULTS

Various types of EEG abnormalities were found, including the occurrence of spikes, irregular high-voltage wave forms, and bilateral asymmetries. All but one of the penicillin-injected Ss displayed some type of EEG abnormality. A few of the saline-injected Ss had atypical or abnormal EEGs, but they were never as pronounced as those found in the penicillin-injected animals. Spiking occurred in the records of 7 of the 10 penicillin-injected Ss. In addition, high-amplitude discharges somewhat slower than true spikes appear in the records of several Ss.

Another type of abnormality common in the EEGs of the penicillin-injected Ss was the occurrence of bursts of high-voltage activity superimposed on a background of low-voltage activity or slow waves. Bursts sometimes would $\mathrm{c}$ ccur bilaterally, but an asymmetry was sometimes observed in which the b irsts were more conspicuous either on the side of the focus or on the contralateral side. 
Frequently, fast spike-like spindles were superimposed on the burst. Periods of low-voltage depressed activity often followed the occurrence of bursts.

All of these abnormalities occurred in the saline group, although with less frequency and less severity than in the penicillin group. This suggests the possibility that tissue damage resulting from the intracortical-injection procedure per se may account for some of the electroencephalographic abnormalities seen.

\section{Activity}

The data for activity in the open field are presented in Table 1 . The mean activity for the penicillin-injected group was greater than that of the saline-injected control group ( $\mathrm{T}$ test, $\mathrm{p}<.01$ ).

\section{Spontaneous Alternation}

Spontaneous alternation between right and left turns in the T-maze failed to differentiate between penicillin- and saline-injected $S s$ on any single day or on all days combined.

\section{Position Learning}

No differences among groups were found in original acquisition or learning of the second reversal problem. In addition, no difference was found among the groups for learning the first reversal to the higher performance criteria, but there was a suggestion that the rate of acquisition of the first reversal for the penicillin-injected animals might be different. Figure 1 presents the mean number of trials required to reach the successively more difficult criteria for the penicillin- and

Table 1

Activity Scores; Number of Lines Crossed in Open Field

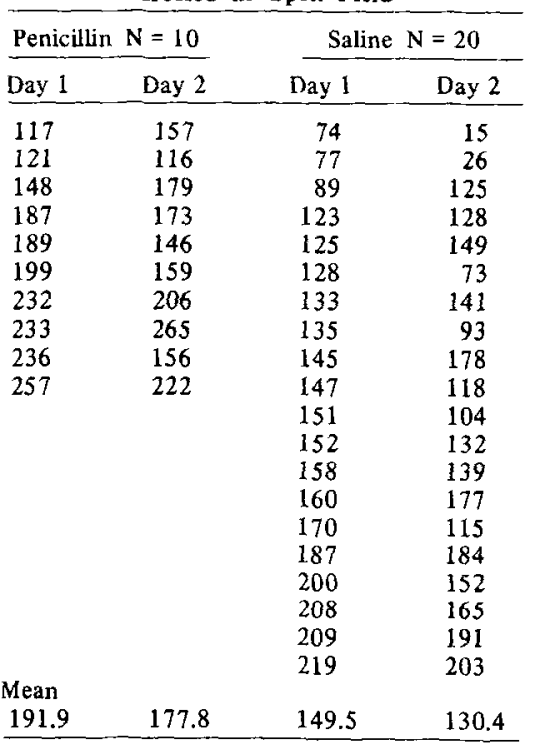

saline-injected (both unilaterally and bilaterally injected) Ss. It should be emphasized that this difference in rate of attaining various criterion levels was found only during training on the first reversal.

\section{Histology}

In the majority of animals, tissue damage attributable to the penicillin application was minimal. Changes produced by the penicillin included destruction of the molecular layer of the cortex and cell reduction in the underlying layers 2 and 3 . There was no apparent relationship between amount of tissue damage and degree of electroencephalographic abnormality.

\section{DISCUSSION}

Differences in the general activity measures were anticipated for a number of reasons. Pilot studies with intracortical penicillin application had produced animals that seemed irritable and overactive in response to handling. This was noticed when the pilot Ss were subjected to various types of stimulation under informal conditions. For example, penicillin Ss were over-responsive to the sound of keys being jingled, a stimulus that will trigger a convulsion in a susceptible animal, although behavioral seizures were not elicited in our animals. Similar irritability has been observed by Goldsmith (1967) and Nakajima (1969).

The spatial-learning task was chosen in order to have a measure that might be related to the type of learning deficit found in the study of Kraft, Pribram, \& Obrist (1960), but our problem failed to differentiate the penicillin- from the saline-injected animals, although there seemed to be a trend toward slower achievement of the first reversal. Nakajima (1969) also found that bilateral injections of Actinomycin D into neocortex failed to interfere with spatial-discrimination learning.

In the present study, there was no apparent correlation between the extent of EEG abnormalities and behavioral performance, but the electrographic recordings were not made during training. As Morrell (1958) has noted, one would ideally like to be able to demonstrate an impairment of a particular function in the "instantaneous presence" of a discharging lesion in the relevant brain area. It is possible, however, that a one-to-one temporal relation between abnormal EEG and behavioral impairment should be expected, since the deficit may reflect some general abnormality of function in "epileptic brain" that exists during inter-ictal normality as well as during epileptiform activity.

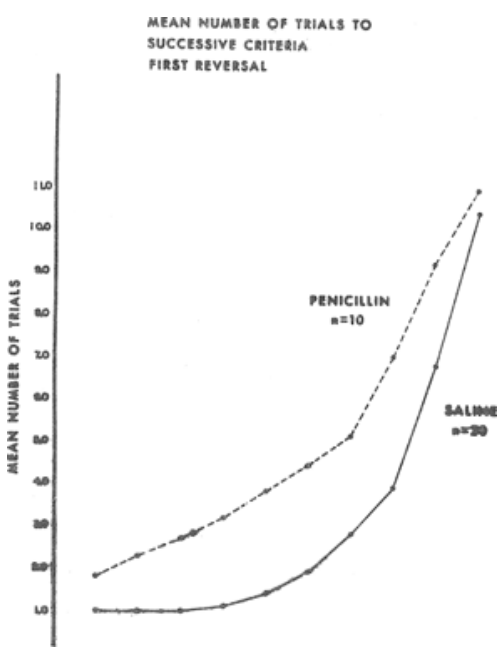

Fig. 1. Mean number of trials to attain successively more difficult criteria of performance during training on first reversal of spatial discrimination. The two groups of saline-injected animals have been combined.

\section{REFERENCES}

CHOW, K. L., \& OBRIST, W. D. EEG and behavioral changes on application of $\mathrm{AL}(\mathrm{OH})$ cream on preoccipital cortex of monkeys. Archives of Neurology \& Psychiatry, 1954, 72, 80-87.

DOUGLAS, R. J., \& ISAACSON, R. L. Homogeneity of single trial response tendencies and spontaneous altemation in the $T$ maze. Psychological Reports, 1965, 16, 87-92.

GOLDSMITH，L. J. The effect of intracerebral actinomycin $\mathrm{D}$ and of electroconvulsive shock on passive avoidance. Journal of Comparative \& Physiological Psychology, 1967, 63, 126-132.

KRAFT, M. S., OBRIST, W. K., \& PRIBRAM, K. H. The effect of irritative lesions of the striate cortex on learning of visual discriminations in monkeys. Joumal of Comparative \& Physiological Psychology, 1960, 53, 17-22.

MORRELL, F. Some electrical events involved in the formation of temporary connections. In H. H. Jasper (Ed.), Reticular formation of the brain. Henry Ford Hospital International Symposium. Boston: Little Brown, 1958.

NAKAJIMA, S. Interference with relearning in the rat after hippocampal injection of actinomycin D. Journal of Comparative \& Physiological Psychology, 1969, 67, 457-461. STAMM, J. S., \& PRIBRAM, K. H. Effects of epileptogenic lesions in frontal cortex on learning and retention in monkeys. Journal of Neurophysiology, 1960, 23, 552-563.

$$
\text { NOTES }
$$

1. This research was supported in part by a grant from the National Institute of Mental Health (NIH-MH-8502) to R. L. Isaacson. We would like to express our appreciation of the contribution of Miss Patricia Duffy to this research.

2. Miss Schuman received support from the Joint Psychopharmacology training grant to the University of Michigan. 